after removal, three feet two inches in its largest circumference, and two feet one inch and $a$ half in its smallest, and weighed twenty-five pounds, presented a smooth shining surface of peritoneal covering. It was a multilocular cystiform tumour, marked by several lines or bands of a denser, whiter, fibrous tissue than the rest of the cyst, corresponding with the septæ of the cysts. The walls of the cysts are composed of three distinct coats:-First, a peritoneal layer; secondly, a middle or fibrous layer of unequal density; and thirdly, a rather thick membranous sac, containing fluid. The peritoneal coat is thin, smooth, and shining, and free from any of those opacities which result from inflammatory action; it is very closely attached to the fibrous layer, except at the pedicle, where it was loosely reflected, and gave passage to several very small arteries, (i. e. very small compared with the size of the tumour), none being larger than a common probe; several much larger returning veins, and several nerves. The middle coat is also thicker at the root, and on it ramify the arteries, veins, and nerves. It varies much in density, and at the periphery of some of the cysts it is very thin. The inner coat has the appearance of having in some of the cysts, two layers. This is more distinct in the smaller than in the larger ones. The membrane is slightly rugous, and varies in colour; in some places pale, in others of a slight ochre colour, with many minute vessels ramifying on it. Some of the cysts are very large, containing three to four pints; some very small, and placed one within another like a nest of boxes; at one point as many as five are so placed. The fluid varies in density and tenacity in the different cysts ; in the smaller ones being clearer and thinner; in the larger, more thick, and of a yellowish green hue. The average specific gravity 1010 . It contains a very large proportion of albumen, more than its specific gravity would have led me to believe. It became putrescent in about fifteen days when exposed, evolving ammonia and sulphuretted hydrogen very freely.

I should estimate the quantity of fluid at about twenty-two or twenty-three pints, counting what was lost at the time of the operation.

\section{CASE OF A RARE VARIETY OF SPINA BIFIDA.}

BY EDWARD T. HUGHES, M.D., Mold.

Read at the North Wales Branch Meeting, held at Denbigh, June 17, 1851.

Jонм M., aged 24, well made, and enjoying robust health, applied to me on the 8th of July, 1846, for advice respecting a tumour situate over the left buttock, which had burst on the previous evening, and discharged a large quantity of a thin, clear, colourless fluid, and to day, during his walk to Mold, a distance exceeding three miles, had continued to do so most profusely. The tumour, previous to bursting, was described to me as being the size of a man's head, and occupied the whole length of the sacrum and coccyx, extending a little over the mesial line on the right side, but on the left covering half the buttock. It was not painful to the touch, except at the part where it had given way, which was rather below its centre. The feel of its lower portion was thick and fleshy, but in the upper, notwithstanding the wrinkled state of the skin evinced its greatly diminished size, fluctuation was evident, and by slight pressure the escape of fluid was materially increased.

The outer envelopes of the tumour appeared to have undergone a gradual process of thinning, and to have given way from this cause rather than from any ulcerative process ; and, deprived of their support, the sac had in like manner been unable to resist the pressure of its contents, which now filtered through a network of delicate fibre, formed by the separation of its tissue, to the extent of a square inch. The external surface of the sacrum was not at all tender to the touch; but at the junction of this bone with the coccyx there was a distinct opening, and the part when pressed was painful. I carefully examined the whole length of the spinal column, and could not discover any defect or tenderness. He had not at any time experienced either numbness or debility of the limbs. His head was well formed. His senses were perfect. The only particular worthy of notice was the dilated state of the pupils, which in no way affected his vision. Beyond the discomfort occasioned by the constant dribbling from the swelling he made no complaint, its reduction in size being rather a relief than otherwise. The fluid, on examination, exhibited slight traces of albumen.

The following history confirmed my opinion that the case was one of spina bifida :-

Soon after birth a tumour, the size of a walnut, was discovered, extending from the junction of the sacrum and coccyx half down the latter bone; at first it increased slowly, but at the age of thirteen was the size of an infant's head. During his earlier years, and when his own recollection will not serve him, his mother states him to have been a healthy boy, with the exception of occasional headaches, which were always brought on by stooping. When nearly twelve years of age he went into farm service, but when the potato and turnip harvests arrived, and he was obliged to stoop much, his headaches became so frequent and violent that he could not remain in his place. He received little sympathy from his employer, as, in other respects, he bore so completely the appearance of strong health. He describes the pain as dull and heavy, referrible to the fore-part of the head, and always relieved by lying down. He was at this time under medical treatment, but received no benefit from it, for the tumour had not as yet appeared in any way to influence his complaints, and was not mentioned. When thirteen years old he struck it, and was immediately seized with intense headache; from being full and firm it became soft and empty, and it was not until (after several days) it recovered its original condition, that his head was relieved. Position had hitherto in no way interfered 
with his comfort, but he could never after this lie on his back without inducing headache. The most remarkable effect, however, was that he no longer felt any inconvenience from stooping, as had previously been the case, but was accustomed to relieve his headaches by bending his head lower than his body, and thus has been able to do work which he could not otherwise have attempted. During the last eight years the tumour had gradually increased to at least double its former size. Whenever he hurt it he uniformly suffered severe headache, it became soft and flaccid, and no relief was ever experienced until, as in the first instance, it recovered its accustomed form. In other respects his general health has been very good, and during the last two years he has worked underground as a lead miner. $\dot{A}$ fortnight ago, while at work, he struck the tumonr a severe blow, and since that occurrence its increase in size has been much more rapid than on any previous occasion, until it burst yesterday.

He was sent home, and directed to apply water dressing to the sore, to remain in bed, and take aperient medicine if required. On the evening of July 10th he had considerable pain in his back, and heat in the tumour, which was relieved by free discharge from it. On the 11th I pressed out about half a pint of curdled matter from it, without pain. He was ordered to lie on his left side, so as to favour the discharge, to continue the water dressings, and to take a dose of saline aperient medicine twice or three times a day. On the 13th he was better, the tumour was of a more fleshy consistence, and much diminished in size. Cn pressing in every direction, not more than a teaspoonful of thick purulent matter was discharged. From this date to the 28th he improved ; the tumour was gradually assuming a firmer feel, and was much diminished in extent; the discharge from it healthy, and in sufficient quantity. His appetite was good, he slept well, and every symptom led to the hope of a favourable result, when on the 29th he was attacked with pain in the head, and along the whole length of the spine. There was no discharge from the sore, and the muscles of the back were in a perfect state of opisthotonos. General and local bleeding, with other active treatment, was unavailing. He became paralyzed, coma supervened, and he died on the morning of the 2nd of August.

I regret that an examination of the body was not allowed.

The foregoing case is interesting, inasmuch as very few of the subjects of spina bifida attain adult age.

A case, in some particulars similar, is related by $\mathrm{Mr}$. Dawson, of Liverpool, in the first volume of the "Transactions" of the Association. The patient, a lady, 38 years of age, had a tumour on the upper and back part of the thigh, about the size of a pomegranate, which was the source of much discomfort to her, and she consulted the late Mr. Park as to the propriety of its removal, for which she was anxious. On manual examination it appeared to be fibro-cartilaginous, with a small quantity of fluid occupying its apex. It had existed from birth, and when first discovered was the size of a filbert. It was punctured, and twelve ounces of clear fluid discharged; after its collapse its connection with the spinal column was traced through an opening between the sacrum and the coccyx. Shelived nineteen days after the operation. The details are long and interesting, and well worth attention.

As the tumour had burst before I saw my patient, I was relieved from those difficulties of diagnosis which spina bifida, in so unusual a situation, might have presented. I had, also, been much interested in the perusal of Mr. Dawson's case, and could not fail to recognize the points of similarity between the two.

Mold, June 25, 1851.

ON THE

\section{MANAGEMENT OF WOMEN AT, AND AFTER} THE CESSATION OF, MENSTRUATION.

\author{
B х E. J. T I L T, M. D.,
}

Senior-Physician to the Farringdon General Dispensary and Lying-in Charity, and to the Paddington Dispensary for Diseases of Women and Children.

\section{Sedatives.}

WHEN ${ }^{-}$relating the successive variations of practice which have occurred in the administration of our most valuable medicines, the medical historian will probably state, that during the last thirty years there has been too much timidity in the employment of sedatives, and particularly in that of opium, for the present generation of medical men seem to forget that often nature only requires to be freed from present pain, to enable an organ to return at once to the regular performance of its function, without future distress or inconvenience. Is it, then, necessary to remind the reader, how generally useful sedatives are, that in most diseases they not only assuage the acuteness of pain, but lull excited action to a slower rate of progress, and to a more subdued tone. The blood-vessels serve under the immediate rule of the accompanying nerves; and hæmorrhage as often depends upon their purturbed agency as on any peculiar state of the blood-ressels themselves; and although other measures may be indispensable, the return of such hæmorrhages can only be prevented by a judicious use of sedatives.

We have already seen how useful is opium in the relief of many deranged states of action, particularly in dysmenorrhœa, and the utility of sedatives in diseases of the change of life might be deduced from the great frequency of cerebro-spinal symptoms at the cessation of menstruation. It will be remembered that I stated their frequency to be-

\section{Cerebral Symptoms.}

Headache, sick-headache, hysteria, and pseudo-narcotism had existed in ...

They were augmented in ... $\quad . . \quad 36$

, remained the same in $\ldots 18$

$\begin{array}{lllll}, & \text { were less in } \ldots & \ldots & \ldots & 10\end{array}$

They did not exist in $\quad \ldots \quad \ldots \quad \ldots \quad 3$

64 per cent.

$$
\text { ," }
$$

